\title{
Células-tronco hematopoéticas de cordão umbilical: uma nova alternativa terapêutica?*
}

\section{Umbilical cord blood hematopoietic stem cells: a new therapeutic allternative?}

\author{
Francisco Costa da Silva Junior ${ }^{1}$, Fatuma Catherine Atieno \\ Odongo', Frederico Luiz Dulley²
}

Silva Jr. FC da, Odongo FCA, Dulley FL. Células-tronco hematopoéticas de cordão umbilical: uma nova alternativa terapêutica? Rev Med (São Paulo). 2009 jan.-mar.;88(1):45-57.

\begin{abstract}
RESUMO: Na medicina, a importância das células-tronco hematopoéticas (CTH) é evidente pelo seu uso rotineiro no tratamento de doenças onco-hematológicas e imunológicas, através do transplante de medula óssea. Entretanto, pelas dificuldades de se encontrar doadores compatíveis de medula óssea, tem-se buscado outras opções, como a utilização de sangue de cordão umbilical (SCU) como fonte celular. O presente trabalho apresenta uma revisão da literatura médica pertinente, analisando os prós e os contras dessa alternativa terapêutica. A despeito do baixo volume coletado e do maior tempo necessário para regenerar o tecido hematopoético, o SCU tem alta concentração de CTH, menor risco de causar doença enxerto versus hospedeiro e maior facilidade de obtenção, contribuindo para sua utilização crescente no mundo. Os novos estudos sobre a utilização do SCU em diferentes formas de terapias celular e gênica tenderão a agregar conhecimento a esse campo de pesquisas.
\end{abstract}

DESCRITORES: Células-tronco hematopoéticas. Transplante de células-tronco de sangue do cordão umbilical. Terapia de genes. Transplante de células.

\footnotetext{
* Trabalho premiado no COMU - 2008. Prêmio Monografias, 2008.

1. Acadêmico do curso de Medicina da Faculdade de Medicina da Universidade de São Paulo.

2. Professor Livre Docente do Departamento de Clínica Médica da Faculdade de Medicina da Universidade de São Paulo, Chefe do Serviço de Transplante de Medula Óssea da Disciplina de Hematologia e Hemoterapia da Faculdade de Medicina da Universidade de São Paulo.

Endereço para correspondência: Francisco Costa da Silva Junior. Rua Teodoro Sampaio, 281. Apart. 31. Cerqueira César, São Paulo, SP. CEP: 05405-000. E-mail: francisco_jun27@yahoo.com.br
} 


\section{INTRODUÇÃO}

C

élula-tronco é uma célula de origem embrionária, fetal ou do adulto capaz de se dividir indefinidamente. Todas as células-tronco, independentemente de sua origem, possuem três características que as distinguem dos outros tipos celulares: a) são células indiferenciadas e não especializadas; b) são capazes de se dividir e se autorrenovar indefinidamente; c) são capazes de se diferenciar em células especializadas quando submetidas a certas condições fisiológicas ou experimentais ${ }^{39}$.

As células-tronco podem ser classificadas em função da sua origem ou da sua capacidade de diferenciação em embrionárias e não embrionárias e totipotentes, pluripotentes e multipotentes, respectivamente. As células totipotentes resultam da divisão celular do óvulo fertilizado e podem dar origem a qualquer tipo de célula ou de tecido que compõe o embrião e que o sustenta durante seu desenvolvimento uterino. A divisão das células totipotentes resulta na formação das células pluripotentes, que são um pouco limitadas na sua diferenciação quando comparadas às células totipotentes. À medida que as células pluripotentes se especializam, passam a constituir tecidos específicos e o seu potencial passa a ser mais restrito, dizendo-se então multipotentes ou células-tronco adultas, cuja função é a reparação e manutenção tecidual (Figura 1).

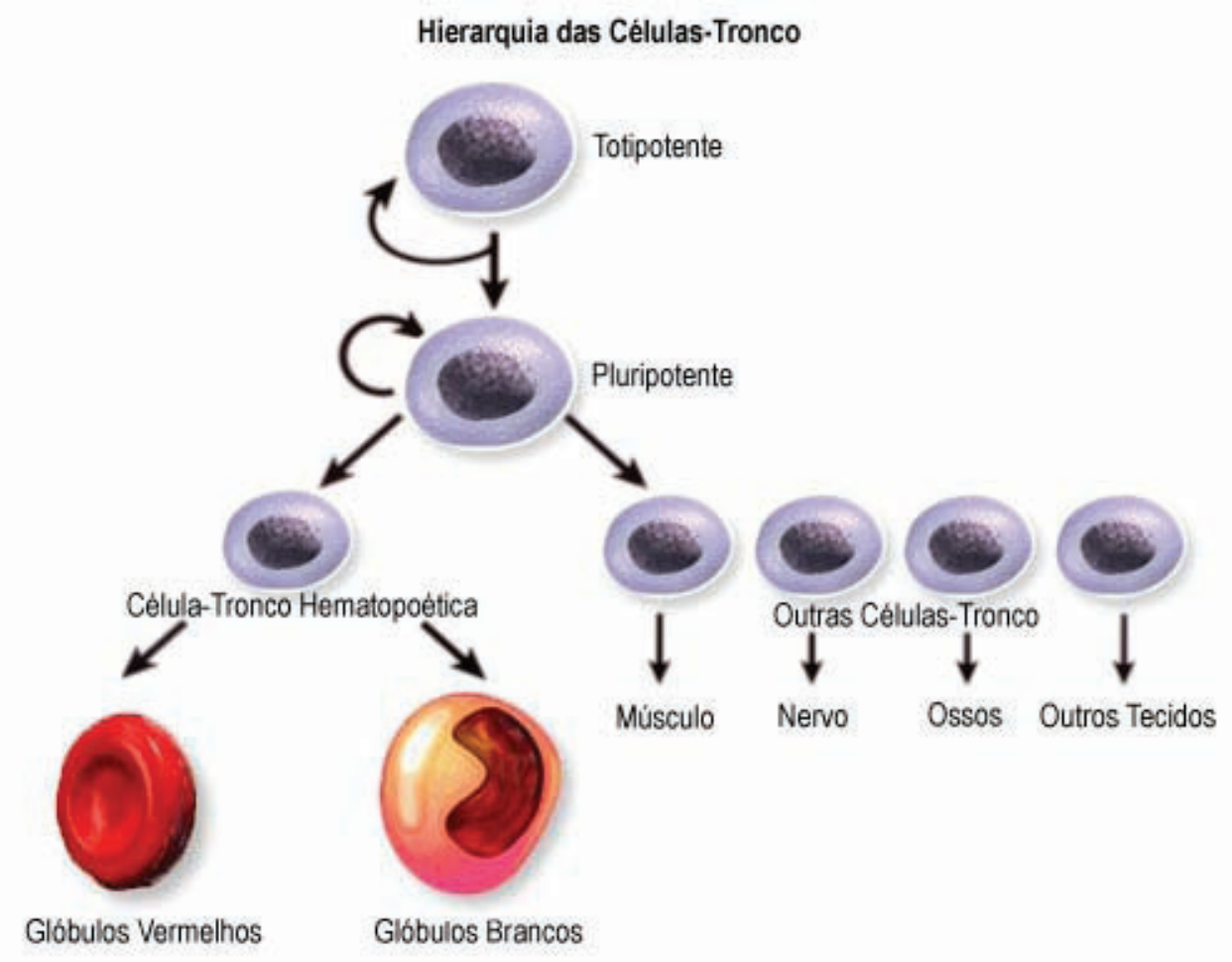

Figura 1. Hierarquia das células-tronco. Na figura são mostradas células-tronco adultas, em particular as células-tronco hematopoiéticas diferenciando-se em glóbulos vermelhos e brancos, que são células especializadas do tecido sanguíneo. Adaptado de: National Institutes of Health (EUA) ${ }^{38}$

Por sua vez, as células-tronco hematopoiéticas $(\mathrm{CTH})$ são células que possuem a capacidade de se autorrenovar e se diferenciar em células especializadas do tecido sanguíneo e células do sistema imune. Elas constituem as células-tronco adultas que têm sido mais bem caracterizadas até hoje. A sua obtenção é feita a partir da medula óssea (considerada a fonte clássica dessas células), do cordão umbilical ou do sangue periférico ${ }^{39}$.

Alguns estudos têm revelado a possibilidade de existirem dois tipos de CTH: células-tronco hematopoiéticas de longo prazo (CTH-LP) e células-tronco hematopoiéticas de curto prazo $(\mathrm{CTH}-\mathrm{CP})^{56}$. As CTH-LP proliferam-se ao longo da vida do organismo, podendo autorrenovar-se em longo prazo e regenerar todos os tipos de células do sangue. As CTH-LP diferenciam-se em CTH-CP, cuja capacidade de se autorrenovar é limitada levando-as a ter uma meiavida de somente poucos meses. As CTH-CP, por sua vez, geram os progenitores multipotentes, que vão 
dar origem aos progenitores comuns das linhagens mieloide e linfoide. As células da linhagem mieloide são eritrócitos, plaquetas, macrófagos, neutrófilos, eosinófilos, basófilos, e as da linhagem linfoide são os linfócitos B e T e células NK. As células dendríticas podem ser tanto da linhagem mieloide como da linfoide. A Figura 2 ilustra o processo de diferenciação das $\mathrm{CTH}$.

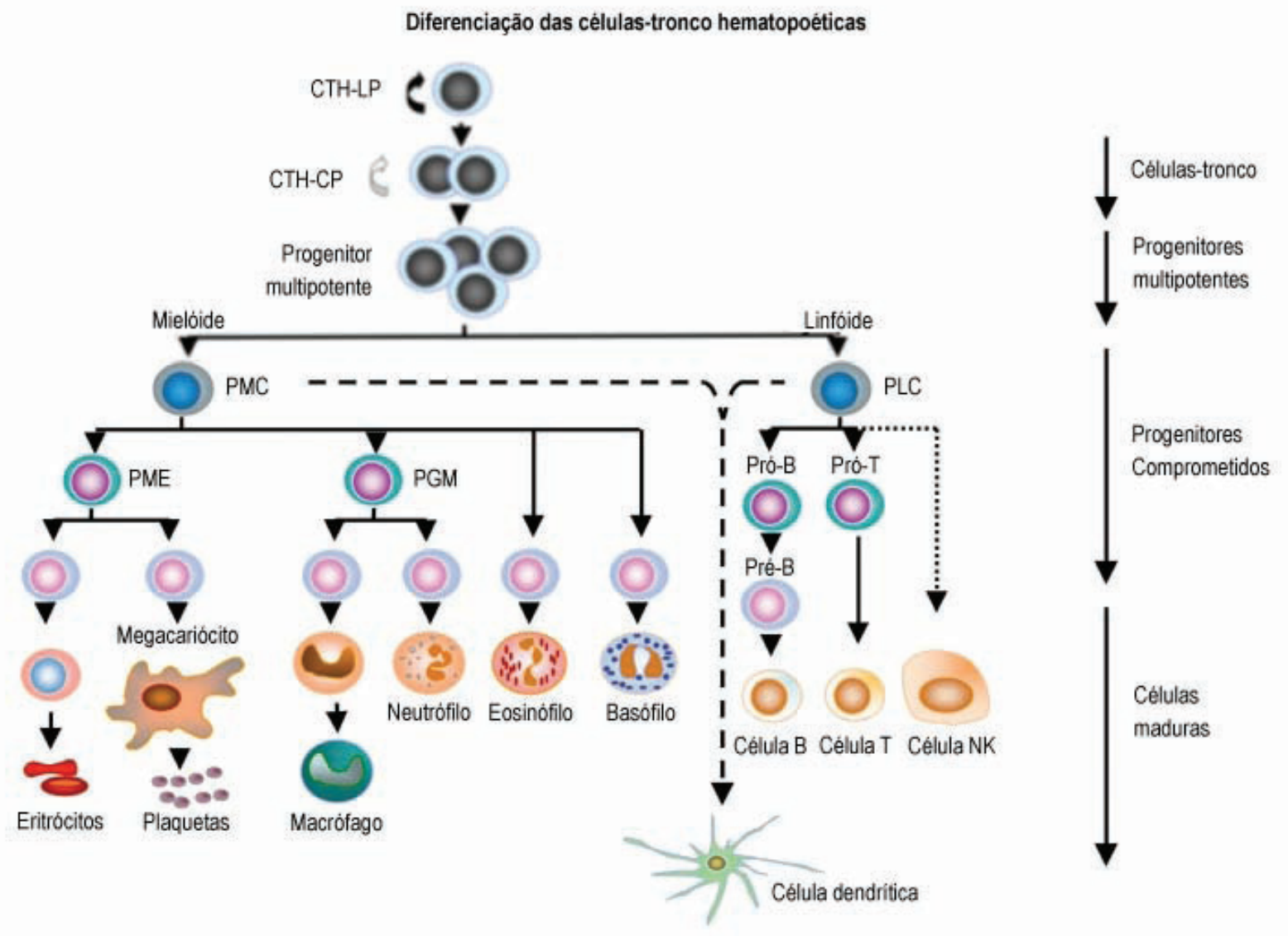

CTH-LP: Células-tronco hematopoéticas de longa duração; CTH-CP: Células-tronco hematopoéticas de curta duração; PMC: Progenitor mieloide comum; PLC: Progenitor linfoide comum; PME: Progenitor megacariocítico/eritrocítico; PGM: Progenitor granulocítico/macrofágico. Adaptado de: Larsson et al. ${ }^{31}$.

Figura 2. Hierarquia e diferenciação das células-tronco hematopoiéticas.

Em suma, células-tronco em diferentes estágios de desenvolvimento guardam peculiaridades quanto à capacidade de renovação e de diferenciação, sendo as células-tronco embrionárias consideradas as mais indiferenciadas e, portanto, potencialmente capazes de originar qualquer tipo de tecido. As CTH, por sua vez, dão origem a tipos celulares mais limitados e não retêm tanta capacidade de renovação quanto as suas precursoras.

Em termos de terapêutica, a terapia com CTH é uma das modalidades de terapia celular que mais tem conseguido eficácia ao longo dos anos no tratamento de doenças malignas e benignas em crianças e adultos. $O$ transplante de medula óssea, por exemplo, é rotineiramente usado no tratamento de linfomas e leucemias e certas condições não malignas, como imunodeficiências congênitas ${ }^{13}$. A
Tabela 1 mostra uma lista das principais doenças tratadas com transplante de CTH.

$\mathrm{O}$ transplante de $\mathrm{CTH}$ pode ser singênico (as células recebidas são de um irmão gêmeo, geneticamente idênticas às do receptor) ou alogênico (as células transplantadas não são geneticamente idênticas às do receptor). Os transplantes autólogos são os realizados com células do próprio receptor ${ }^{13}$. Os transplantes alogênicos guardam o risco de desencadearem uma reação enxerto versus hospedeiro, na qual linfócitos transplantados geram uma resposta imune contra os tecidos do receptor. Em certos casos, como no tratamento de neoplasias, essa reação aumenta a eficiência do tratamento na medida em que os linfócitos transplantados atacam as células neoplásicas remanescentes no receptor ("enxerto versus neoplasia") ${ }^{13}$. 
Silva Jr. FC da et al. Células-tronco hematopoéticas de cordão umbilical: uma nova alternativa terapêutica?

Tabela 1. Principais doenças atualmente tratadas com células-tronco hematopoéticas

\begin{tabular}{ll}
\hline Transplantes autólogos & Transplantes alogênicos \\
\hline & Neoplasias \\
& Leucemia mieloide aguda \\
& Leucemia linfoblástica aguda \\
& Leucemia mieloide crônica \\
Síndromes mielodisplásticas \\
Neoplasias & Doenças mieloproliferativas \\
Lieloma múltiplo & Linfoma não Hodgkin \\
Linfoma não Hodgkin & Linfoma Hodgkin \\
Leucemia mieloide aguda & Leucemia linfocítica crônica \\
Neuroblastoma & Mieloma múltiplo \\
Câncer ovariano & Leucemia mieloide crônica juvenil \\
Tumores de células germinativas & Neuroblastoma \\
& Carcinoma renal \\
Outras doenças & \\
Algumas doenças autoimunes & Outras doenças \\
Amiloidose & Anemia aplástica grave \\
& Hemoglobinúria paroxística noturna \\
& Anemia de Fanconi \\
& Anemia de Blackfan-Diamond \\
& Talassemia maior \\
\hline & Anemia falciforme \\
Imunodeficiência combinada grave (SCID) & Imunodeficiência com hiper lgM \\
& Deficiência de adesão leucocitária \\
& Doença linfoproliferativa ligada ao X \\
& Erros inatos do metabolismo \\
\hline
\end{tabular}

Adaptado de: Copelan ${ }^{13}$ e Locateli et al. ${ }^{34}$.

\section{HISTÓRICO DAS CTH}

$\mathrm{Na}$ época da 2a Guerra Mundial, o sangue placentário armazenado era usado como uma fonte de sangue para transfusão ${ }^{42}$. Em 1959, Thomas foi o pioneiro em utilizar o transplante de medula óssea no tratamento de uma paciente com leucemia submetida à irradiação corporal total. Neste caso, tratava-se de um transplante singênico, em que as células eram provenientes da irmã gêmea da paciente ${ }^{13}$. Somente em 1963, entretanto, é que as CTH puderam ser mais bem caracterizadas por James Till, Ernest McCullogh e Lou Siminovitch, utilizando modelos animais ${ }^{21}$. No início da década de 1960, com a identificação dos genes do complexo HLA (Antígenos Leucocitários Humanos), o transplante alogênico de medula óssea tornou-se possível ${ }^{13}$.

As células-tronco de cordão umbilical, por sua vez, foram usadas terapeuticamente pela primeira vez, por Eliane Gluckman, numa criança com anemia de Fanconi em 1988 ${ }^{18,19}$, a qual recebeu CTH de seu irmão HLA-compatível ${ }^{19}$. A tipagem do HLA foi feita enquanto a mãe da criança ainda estava grávida ${ }^{19}$. Desde então, o número de transplantes de CTH de cordão umbilical tem crescido rapidamente, a maioria envolvendo doadores com o HLA idêntico ao dos receptores ou parcialmente compatível ${ }^{19}$.

\section{POTENCIALIDADES DAS CTH}

As células-tronco hematopoéticas são multipotentes, uma vez que retêm a capacidade de originar diversos tipos celulares, e expressam a molécula CD34 em sua superfície. Como precursoras das células diferenciadas, as células-tronco precisam se dividir a fim de manterem a população de células indiferenciadas. As CTH dão origem às células sanguíneas e linfáticas que constituem o organismo. Entretanto, certos estudos têm questionado as limitações de plasticidade tradicionalmente atribuídas às CTH $33,5,8,13,15,16,39,45,50$.

Num dos primeiros estudos nessa área, Ferrari et al. ${ }^{16}$ concluíram que CTH de medula óssea injetadas no interior de músculo esquelético tomavam parte da regeneração muscular após lesão tecidual. Utilizando transplante de CTH num modelo murino de distrofia muscular de Duchenne, Bittner et al. ${ }^{7}$ verificaram que $\mathrm{CTH}$ da medula óssea de ratos 
tinham o potencial de se diferenciar em fibras musculares esqueléticas ou mesmo fibras musculares cardíacas a partir do recrutamento de células-tronco da medula óssea. Em outro estudo, viu-se que CTH selecionadas podem sofrer "homing" para os músculos lesados, esquelético ou cardíaco, e regenerar esses tecidos ${ }^{8}$.

Eglitis e Mezey ${ }^{15}$ foram os primeiros a demonstrar que CTH de medula óssea eram capazes de se diferenciar em micróglia e astróglia no interior do sistema nervoso central (SNC) num modelo animal. Asheuer et al. ${ }^{5}$ demonstraram recentemente que células CD34+ humanas diferenciam-se em micróglia de roedores.

Petersen et al. ${ }^{45}$ mostraram que CTH da medula óssea de ratos eram capazes de originar hepatócitos em receptores pré-tratados com 2-acetilaminofluoreno, um supressor de proliferação hepática, e tetracloreto de carbono, um indutor de lesão hepática. Transplante de medula óssea de um animal saudável foi capaz de salvar os animais da lesão hepática intensa por meio da transdiferenciação das CTH em hepatócitos e células ductais. Num outro estudo ${ }^{50}$, os ratos tinham a totalidade de seu corpo irradiada, após o que eram submetidos ao transplante de medula óssea. Foi observada a presença de hepatócitos maduros derivados dos doadores no fígado dos ratos receptores, fortalecendo a hipótese de que CTH transplantadas tenham participado da regeneração hepática ${ }^{50}$. Em humanos, o achado de hepatócitos de pessoas do sexo maculino em pacientes femininas que receberam transplante de medula óssea de doadores do sexo masculino sugere que algumas CTH da medula óssea tenham capacidade de se integrar no fígado e formar hepatócitos ${ }^{3}$.

Deve-se ressaltar, contudo, que as célulastronco da medula óssea utilizadas nesses experimentos presumivelmente sejam representadas, em sua maior parte, por $\mathrm{CTH}$, embora células-tronco estromais, mesenquimais, também possam tomar parte de alguns dos resultados relatados. Sabe-se, por exemplo, que células-tronco mesenquimais de medula óssea, após serem injetadas por via intravascular em ratos previamente irradiados, são encontradas no cérebro expressando marcadores neuronais, o que sugere terem sofrido diferenciação em células do parênquima do $\mathrm{SNC}^{9,36}$. Alguns estudos, contudo, têm demonstrado que a regeneração hepática de fato pode ser obtida a partir de CTH, mesmo na ausência de células mesenquimais de medula óssea ${ }^{30,55}$.

Nierhoff et al. ${ }^{41}$ demonstraram que após transplante hepático, células CD34+ do doador eram encontradas na medula óssea do receptor. No estudo de Körbling et al. ${ }^{29}$, células-tronco derivadas de sangue periférico conseguiram se diferenciar em hepatócitos maduros e células epiteliais da pele e do trato gastrointestinal. Apesar de a magnitude da repopulação ser mínima, esse estudo sugere a possibilidade de geração de hepatócitos derivados do doador após um transplante de CTH. Ishikawa et al. ${ }^{23}$, por sua vez, demonstraram que células CD34+ humanas derivadas de cordão umbilical ou medula óssea têm a capacidade de regenerar células epiteliais gastrointestinais.

A possibilidade de reparação miocárdica após um infarto através do transplante de CTH tem gerado grande entusiasmo nos pesquisadores. Num modelo animal, Orlic et al ${ }^{43}$ demonstraram a regeneração de cardiomiócitos após infarto do miocárdio através da administração direta de CTH de medula óssea no miocárdio saudável, adjacente ao local do infarto. Após 9 dias, foi possível observar uma regeneração miocárdica a partir das CTH transplantadas ${ }^{43}$. Jackson et al. ${ }^{24}$ puderam confirmar o potencial cardiomiogênico das $\mathrm{CTH}$ em experimentos envolvendo animais. Através do transplante de CTH alogênicas, Kocher et al. ${ }^{26}$ verificaram que CTH de medula óssea poderiam contribuir para a neovascularização de corações infartados através da diferenciação em células endoteliais. Tais pesquisas indicam que, apesar de mais estudos serem necessários para confirmar os achados, o potencial das CTH vai além da (re)constituição imunológica e hematológica dos indivíduos.

\section{QUESTÕES ENVOLVENDO A DIFERENCIAÇÃO DAS CTH}

\section{Estímulo deflagrador}

A partir dos estudos sobre a transdiferenciação de CTH a diversos tipos celulares, pode-se concluir, como princípio geral, a necessidade de um estímulo inicial à regeneração do tipo celular correspondente antes que as CTH efetivamente modifiquem seu fenótipo ${ }^{21}$.

Esse estímulo inicial tem sido simulado nos experimentos por meio de uma injúria artificialmente induzida ou, no caso do desenvolvimento fetal e neonatal, a demanda geral de crescimento de todos os sistemas de órgãos ${ }^{21}$. Por exemplo, a transdiferenciação de CTH a hepatócitos pode ser conseguida por meio da exposição do animal à radiação ou lesão química ao fígado $6,30,55$. A conversão das CTH a cardiomiócitos somente ocorre após a indução de um infarto do miocárdio ${ }^{43} \mathrm{e}$ a transdiferenciação a células endoteliais após a isquemia induzida pela ligação de uma artéria coronária ${ }^{26}$. Portanto, a diferenciação das CTH somente ocorreu após o surgimento da necessidade de crescimento tecidual. Quais fatores são responsáveis por isso ainda não foram totalmente descobertos. 
Silva Jr. FC da et al. Células-tronco hematopoéticas de cordão umbilical: uma nova alternativa terapêutica?

\section{Via de administração}

O local de administração das CTH interfere no processo de endereçamento ("homing") dessas células até seus sítios-alvo. Embora a maioria dos estudos se utilize da via intravascular para a transferência de $\mathrm{CTH}$, alguns poucos estudos têm estudado alternativas à essa via, como a injeção intramiocárdica utilizada no estudo de Kocher et al. ${ }^{26}$.

Há que se considerar que, após uma lesão tecidual, por exemplo, certos mediadores inflamatórios são responsáveis por recrutar células-tronco locais ou distantes, como da medula óssea, até o sítio de regeneração tissular ${ }^{44}$.

Os detalhes do processo de endereçamento de $\mathrm{CTH}$, as citocinas envolvidas, as moléculas de adesão importantes e a melhor via de administração a ser considerada em cada caso são algumas questões que precisam ser respondidas antes da ampla utilização terapêutica da terapia celular com CTH para doenças em que essa alternativa de tratamento ainda não tenha sido bem estabelecida.

Equilíbrio entre autorrenovação e diferenciação das CTH

As células-tronco possuem duas propriedades intrínsecas: a capacidade de autorrenovação da população de células indiferenciadas e o potencial de diferenciação a tipos celulares mais avançados na escala ontogenética. A maior ou menor quiescência das CTH relaciona-se à sua tendência a permanecerem indiferenciadas, gerando novas células-tronco a cada mitose, ou à tendência à diferenciação celular. Um fino equilíbrio existe neste balanço de modo a regular o comportamento das células-tronco do organismo.

Após o estímulo inicial e o endereçamento ao local da injúria tissular, alguns elementos regulam o comportamento das $\mathrm{CTH}$, quais sejam: o microambiente do local da lesão; os fatores solúveis circulantes no momento; o programa genético seguido pelas $\mathrm{CTH}$; e seu estado corrente de diferenciação celular.

Vias intrínsecas e extrínsecas são envolvidas na regulação da regeneração das $\mathrm{CTH}^{1}$. As vias intrínsecas incluem proteínas antiapoptose (BCL2 - BCell Lymphoma 2 e MCL1 - Myeloid Cell Leukemia 1), fatores de transcrição (Tel - Translocation Ets Leukemia) e transdutores de sinal (Pten - Phosphatase and Tensin). A via extrínseca é basicamnte relacionada ao microambiente no qual as $\mathrm{CTH}$ se encontram e as interações celulares e extracelulares ${ }^{11,36}$. Alguns autores têm argumentado que as células estromais do sítio da lesão são responsáveis pela renovação da população de células-tronco, o que se associa a sinais opostos partindo de outros elementos que promoveriam a diferenciação das células-filha ${ }^{25}$. Outros autores concluíram que uma combinação de moléculas de adesão e citocinas podem promover efeitos similares ${ }^{20,57}$. De qualquer maneira, tem sido demonstrado que a diferenciação celular em geral ocorre no sentido do tipo celular predominante no local de destino das CTH, e não de acordo com seus órgãos de origem²1.

Várias citocinas têm sido estudadas e utilizadas na modulação do processo de autorrenovação e de diferenciação das CTH. Yang et al. ${ }^{57}$ constataram que o interferon(IFN)- $\gamma$ reduz a renovação da população de CTH, estimulando sua diferenciação. Sierget et al. ${ }^{49}$ conduziram um estudo que mostrou que a interleucina(IL)-3 estimula a proliferação de CTH de cordão umbilical na medula óssea, sangue periférico e baço de camundongos da linhagem NOD/SCID (nonobese diabetic/severe combined immunodeficient).

Um desequilíbrio entre os dois pólos comportamentais das células-tronco podem levar, por exemplo, à proliferação descontrolada, eventualmente originando um teratocarcinoma, como de fato tem sido verificado em alguns experimentos com célulastronco embrionárias ${ }^{22}$.

\section{Modelos animais e estudos ex vivo}

Boa parte dos estudos envolvendo CTH têm utilizado transplantes xenogenéticos em ratos transgênicos imunodeficientes ou ovelhas pré-imunes que servem como modelos para o crescimento tecidual e diferenciação das CTH humanas ${ }^{21}$.

Utilizando o modelo ovino fetal, Almeida-Porada et al. ${ }^{4}$ demonstraram que diferentes populações de CTH humanas altamente purificadas derivadas de medula óssea de adultos e sangue periférico eram capazes de originar células mesenquimais após o transplante, fortalecendo a hipótese de que esse modelo é capaz de permitir que células-tronco humanas transplantadas possam se diferenciar a certos tipos celulares, inclusive modificando sua identidade genética embrionária de hematopoética para mesenquimal $^{21}$. Zanjani et al. ${ }^{58}$, por sua vez, verificaram que CTH humanas de medula óssea ou cordão umbilical originavam hepatócitos humanos funcionais nesses modelos ovinos fetais.

\section{PECULIARIDADES DAS CTH DE CORDÃO UM- BILICAL}

Os transplantes autólogos de CTH provenientes da medula óssea ou do sangue periférico 
atualmente são mais utilizados do que os transplantes alogênicos ${ }^{13}$. Entretanto, uma vez que as células-tronco autólogas não induzem reação enxerto versus hospedeiro, elas são menos eficientes que as alogênicas no tratamento de neoplasias. A tolerância à reação enxerto versus hospedeiro é menor nos idosos, e sua intensidade está diretamente relacionada ao grau de incompatibilidade entre o HLA do receptor e do doador ${ }^{13}$.

A procura por $\mathrm{CTH}$ alogênicas histocompatíveis é uma tarefa difícil e demorada. Isso confere grande importância à obtenção de células-tronco a partir do sangue de cordão umbilical e de placenta armazenados em bancos criopreservados ${ }^{13}$.

Embora o sangue de cordão umbilical e de placenta seja rico em $\mathrm{CTH}$, são obtidas em pequenos volumes ${ }^{13,34}$, o que tem limitado sua utilização a receptores jovens, na maioria dos $\operatorname{casos}^{34}$. Apenas um terço dos transplantes envolvendo $\mathrm{CTH}$ de cordão umbilical é destinado a adultos ${ }^{47}$. Além disso, como a reconstituição hematológica e imunológica é mais lenta nos transplantados com células de cordão umbilical ${ }^{2}$, os pacientes ficam mais suscetíveis a infecções logo após o transplante ${ }^{13}$. Apesar dos problemas, a procura por um doador compatível é potencialmente mais rápida (nem sempre) do que nos outros casos, principalmente porque a compatibilidade de HLAs pode ser menos estringente do que no transplante de células-tronco a partir de outras fontes, uma vez que as células-tronco de cordão umbilical desencadeiam menos reação enxerto versus hospedeiro ${ }^{2,13}$.

Gluckman ${ }^{19}$ enumera como possíveis causas das taxas reduzidas de doença enxerto versus hospedeiro a pouca idade dos doadores e dos receptores, a ausência de imunizações prévias ou ativação de células dos doadores por agentes infecciosos, o pequeno número de linfócitos presentes no sangue de cordão umbilical, o efeito imunossupressor de células maternas contaminantes ou a imaturidade do sistema imunológico ao nascimento. Sabe-se que o sangue de cordão umbilical é rico em linfócitos "naïve", alguns dos quais podem apresentar um fenótipo imunossupressor ${ }^{19}$.

As CTH provenientes do sangue periférico, por sua vez, proporcionam um restabelecimento mais rápido de neutrófilos e plaquetas, apesar de haver uma maior incidência de doença enxerto versus hospedeiro ${ }^{40}$. Várias outras diferenças foram descritas em relação às $\mathrm{CTH}$ de diferentes fontes ${ }^{32,40}$. As bases moleculares de tais diferenças traduzem-se por uma expressão gênica diferencial de fatores de transcrição, genes relacionados à regulação do ciclo celular, genes de controle da apoptose e genes envolvidos na adesão e no endereçamento de células-tronco ${ }^{40}$. CTH de medula óssea contêm mais progenitores mieloides do que as CTH de cordão umbilical, além de terem uma atividade mitótica mais intensa e um menor potencial apoptótico ${ }^{40}$. CTH de cordão umbilical, por sua vez, apresentam uma menor dependência de comunicação intercelular com o estroma, apresentam mais células quiescentes e têm um maior potencial de diferenciação celular ${ }^{40}$. Além disso, as CTH de cordão umbilical apresentam um maior potencial de migração do que as CTH de outras fontes, apesar de sua capacidade de adesão celular ser diminuída ${ }^{32}$.

Kolar et al ${ }^{32}$ verificaram que linfócitos oriundos de diversas fontes (fetais, de cordão umbilical e de adultos) retêm uma capacidade similar de geração de diversidade de imunoglobulinas, o que assegura, por exemplo, que transplantes de CTH de cordão umbilical não provoquem algum tipo de imunodeficiência nos pacientes receptores.

Alguns autores têm demonstrado que o sangue de cordão umbilical é enriquecido com células CD34+, a maioria pertencentes a um compartimento mais imaturo CD38- ${ }^{-19}$. As colônias obtidas dessas populações específicas de CTH são maiores e têm um maior potencial de expansão a longo prazo em culturas de células ${ }^{51}$.

Vormoor et al. ${ }^{54}$ constataram que CTH de cordão umbilical proliferam-se a altas taxas em ratos imunodeficientes, diferenciando-se em células da linhagem mieloide e linfoide, mesmo sem a utilização de citocinas que pudessem estimular a proliferação das $\mathrm{CTH}$. Isso enfatiza a ideia de que as diferenças entre a hematopoese adulta e fetal não são apenas quantitativas, havendo também um componente ontogenético relacionado a diferenças na sinalização celular e necessidade de receptores de fatores de crescimento ${ }^{19}$.

Nasagawa et al. ${ }^{37}$, por sua vez, demonstraram num estudo experimental em ratos que CTH de cordão umbilical proliferam em diferentes taxas e de diferentes maneiras conforme o compartimento anatômico em que elas se alojam, como o baço e a medula óssea, após serem estimuladas com substâncias mitogênicas. Isso chama a atenção para a diversidade de questões que as novas propostas de terapia celular têm que responder antes de serem aplicadas em humanos, ponderando a influência do microambiente sobre as CTH.

Também há evidências de que a utilização de terapia gênica envolvendo CTH é facilitada se as células-tronco forem provenientes do cordão umbilical ${ }^{59}$.

Vários estudos têm procurado realizar uma expansão ex vivo da população de CTH de cordão umbilical a fim de aumentar a oferta de célulastronco a serem transplantadas ${ }^{12}$. Além disso, estuda-se a combinação de diferentes fontes de 
Silva Jr. FC da et al. Células-tronco hematopoéticas de cordão umbilical: uma nova alternativa terapêutica?

CTH a serem utilizadas num mesmo receptor ${ }^{13}$. A Tabela 2 mostra algumas estratégias que poderão ser usadas para aumentar a oferta de CTH de cordão umbilical, e a Tabela 3 sumariza os prós e os contras envolvidos na utilização terapêutica dessas CTH.

Tabela 2 Algumas estratégias para contornar os baixos volumes de células-tronco hematopoéticas de cordão umbilical

\begin{tabular}{|c|c|}
\hline Conceito & Solução \\
\hline Aumentar a população de $\mathrm{CTH}^{*}$ a sofrer proliferação & $\begin{array}{l}\text { Transplante duplo de CTH (pelo menos } 1 \text { unidade proveniente } \\
\text { de cordão umbilical) }\end{array}$ \\
\hline $\begin{array}{l}\text { Utilizar células do hospedeiro para reforçar a prolife- } \\
\text { ração }\end{array}$ & $\begin{array}{l}\text { Regimes preparatórios não mieloablativos ou regimes mielo- } \\
\text { ablativos de intensidade reduzida }\end{array}$ \\
\hline Melhorar o direcionamento das CTH & $\begin{array}{l}\text { Injeção direta de CTH na medula óssea ou outro local apro- } \\
\text { priado conforme a doença tratada }\end{array}$ \\
\hline Aumentar o número de $\mathrm{CTH}$ & Expansão ex vivo da população de CTH \\
\hline Modular a proliferação das CTH & $\begin{array}{l}\text { Utilização de citocinas regulatórias, células T regulatórias ou } \\
\text { CTH previamente submetidas à transfecção gênica }\end{array}$ \\
\hline
\end{tabular}

${ }^{*} \mathrm{CTH}=$ células-tronco hematopoéticas. Adaptado de: O'Brien et al. ${ }^{42}$.

Tabela 3. Vantagens e desvantagens da utilização terapêutica de células-tronco hematopoéticas de cordão umbilical

\begin{tabular}{ll}
\hline Vantagens & Desvantagens \\
\hline - Não requer alta estringência na compatibilidade HLA & - Pequeno volume disponível \\
- Prontamente disponível & - Mais demorado para regenerar o tecido hematopoético \\
- Menos doença enxerto versus hospedeiro & do receptor (maior risco de infecção) \\
- Alta concentração de CTHº & Impossibilidade de usar outras CTH a partir da mesma \\
- Maior possibilidade de utilização de um transplante & coleção de sangue de cordão umbilical caso o primeiro \\
autólogo se o sangue de cordão umbilical do próprio & - Resultados de longo prazo são pouco conhecidos \\
- paciente tiver sido colhido ao nascimento & - Como a história genética das CTH de cordão umbilical \\
- Menos risco de contaminação por vírus & pode ser relativamente desconhecida, há algum risco \\
& de transmissão de doenças genéticas \\
\hline
\end{tabular}

${ }^{*} \mathrm{CTH}=$ células-tronco hematopoéticas.

\section{COLETA, PROCESSAMENTO E ARMAZENAMEN- TO DAS CTH DE CORDÃO UMBILICAL}

Os protocolos de coleta e utilização das $\mathrm{CTH}$ de cordão umbilical variam entre as instituições. Todavia, certas premissas são bastante frequentes, quais sejam: (a) antes ou imediatamente após a coleta do sangue de cordão umbilical e da placenta, a mãe deve assinar um termo de consentimento livre e esclarecido; (b) o sangue placentário geralmente é colhido após o parto; (c) o sangue do cordão umbilical é colhido através da punção da veia umbilical e armazenado numa seringa ou numa bolsa apropriada; (d) o processamento geralmente é feito até $24 \mathrm{~h}$ da coleta e envolve testes de controle de qualidade, remoção de plasma e de hemácias a fim de reduzir o volume da amostra; (e) as CTH são armazenadas em bolsas apropriadas e criopreservadas em nitrogênio líquido ${ }^{53}$.

A criopreservação das CTH de cordão umbilical é um fator crítico para a viabilidade da utilização de bancos de sangue de cordão umbilical. Sabe-se que as CTH dessa fonte retêm grande parte de seu potencial mesmo após mais de 15 anos de criopreservação ${ }^{10}$.

\section{BANCOS DE SANGUE DE CORDÃO UMBILICAL}

Há basicamente dois tipos de bancos de sangue de cordão umbilical: os públicos, nos quais o sangue criopreservado fica disponível para pesquisa ou transplante, e os privados, gerenciados por empresas que cobram para armazenar o sangue de cordão umbilical de seus clientes para que possam ser usados no futuro, se necessário ${ }^{52}$. Pouca atenção tem sido dada à criação e ao aprimoramento de bancos de sangue de cordão umbilical de irmãos, o que é especialmente útil quando há algum caso de uma doença tratável com CTH na família ${ }^{46}$.

A alta concentração de CTH no sangue de cordão umbilical e de placenta, a baixa incidência de doença enxerto versus hospedeiro após esse tipo de transplante e as expectativas terapêuticas das $\mathrm{CTH}$ encorajam à criação de bancos de cordão umbilical 
visando transplantes autólogos ou alogênicos ou mesmo pesquisas científicas na área ${ }^{19}$.

Atualmente, há mais de 260 mil unidades de sangue de cordão umbilical armazenadas em dezenas de bancos de sangue de cordão umbilical em vários países do mundo (Figura 4$)^{14}$. A medula óssea continua sendo a principal fonte de CTH nos transplantes realizados no mundo, mas fontes alternativas de CTH (sangue periférico e de cordão umbilical) têm ganhado importância crescente nos últimos anos (Figura 3) ${ }^{14}$. Em 2001, o Instituto Nacional de Câncer (INCA) inaugurou o Banco de Sangue de Cordão Umbilical e Placentário (BSCUP), o primeiro banco desse tipo do Brasil, visando aumentar as chances de localização de doadores para os pacientes que necessitam de transplante de medula óssea e ampliar a rede de bancos de sangue de cordão umbilical no país. Atualmente, o número de bancos é maior, mas a ampliação dos bancos no Brasil ainda é necessária.

\section{Transplantes de células-tronco hematopoéticas segundo a fonte celular (EUA)}

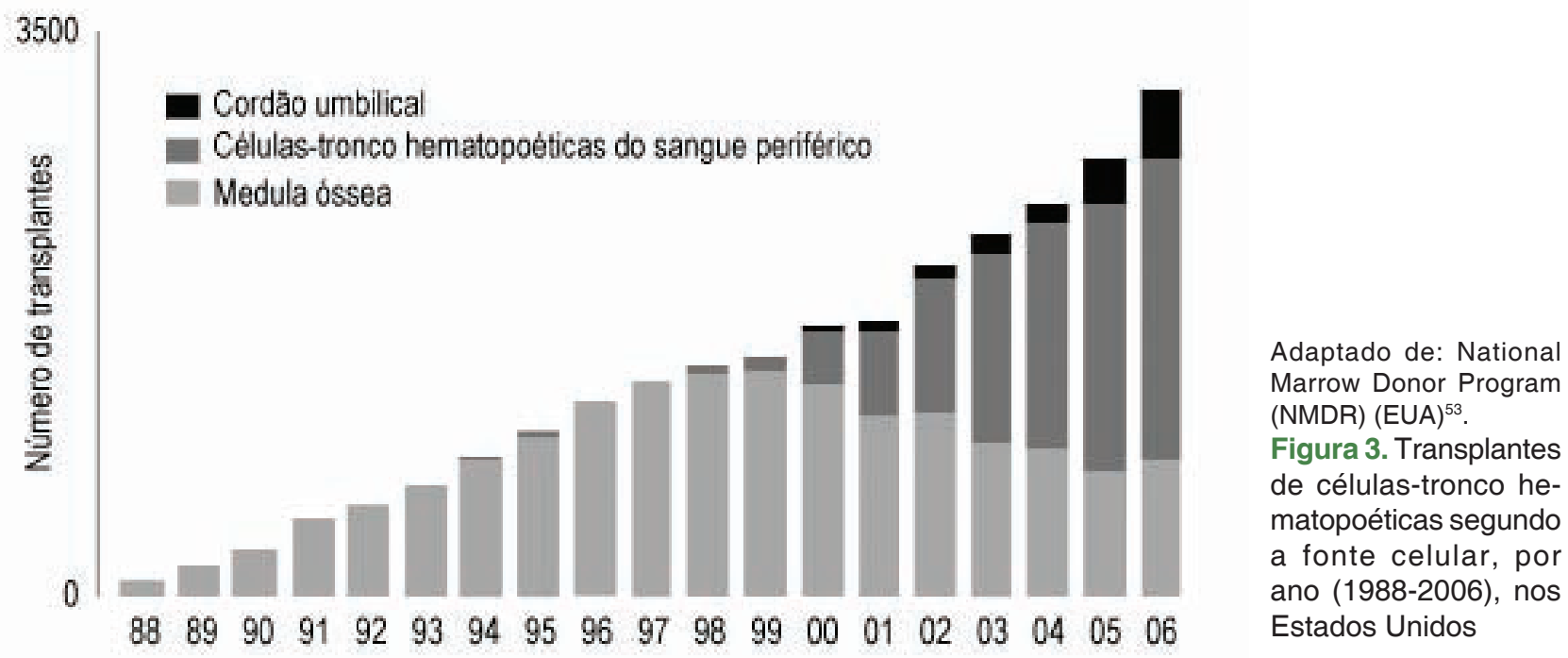

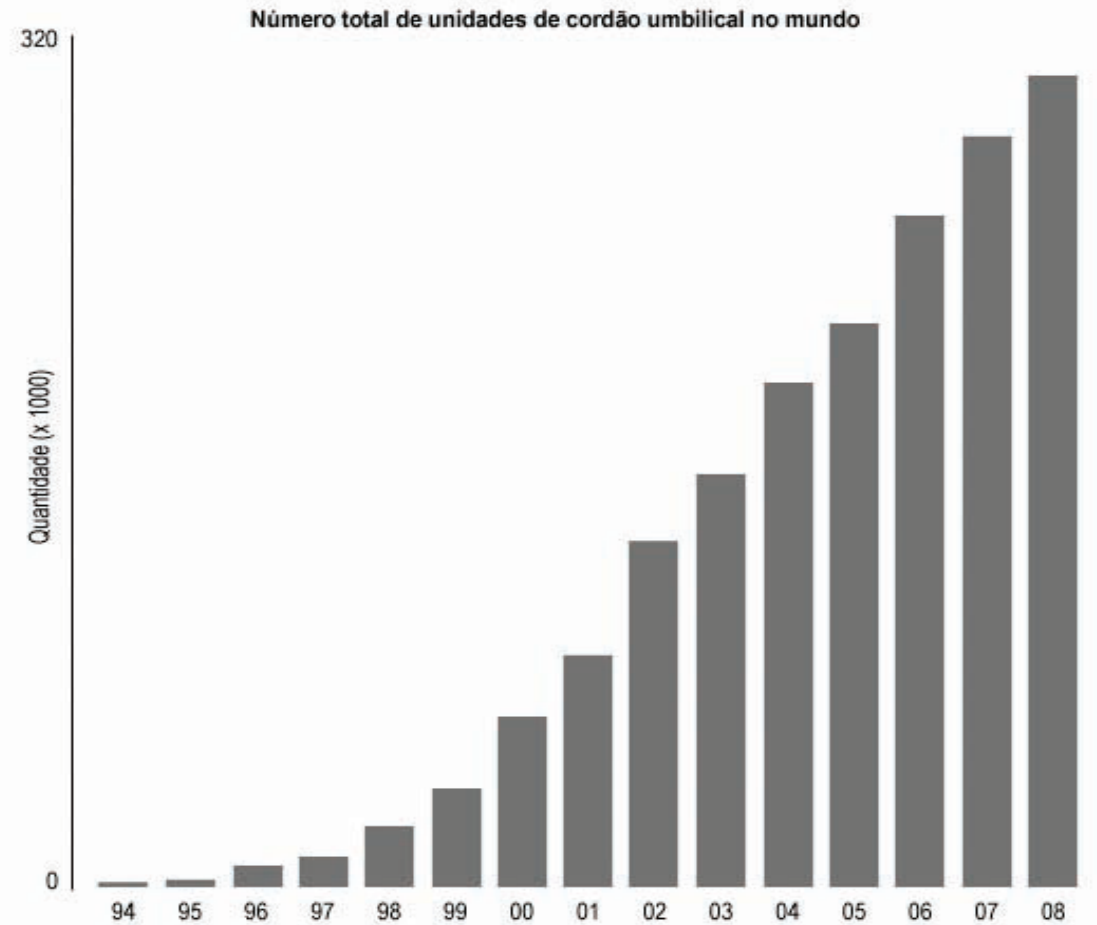

Fonte: Bone Marrow Donors Worldwide (BMDW), $2008^{14}$.

Figura 4. Número de unidades de cordão umbilical armazenadas em bancos de cordão umbilical no mundo, por ano 
Silva Jr. FC da et al. Células-tronco hematopoéticas de cordão umbilical: uma nova alternativa terapêutica?

\section{PERSPECTIVAS FUTURAS}

A utilização de CTH de cordão umbilical como alternativa terapêutica e na pesquisa científica tem sido algo bastante promissor. Dentre as possíveis aplicações científicas, pode-se citar os estudos sobre as particularidades da hematopoese fetal e neonatal, bem como sobre as propriedades das CTH na diferenciação tecidual. Há, ainda, uma crescente área de pesquisas voltadas à tranferência de genes para as CTH visando a futuros estudos de terapia gênica ${ }^{19}$.

Vários estudos têm procurado incorporar estratégias de terapia gênica às CTH a fim de melhorar sua eficiência terapêutica. Kohn et al. ${ }^{27}$ introduziram um gene da enzima adenosina deaminase (ADA) em células de cordão umbilical de 3 crianças com deficiência de ADA cujas CTH dos cordões umbilicais foram coletadas ao nascimento, transfectadas no laboratório e reinfundidas posteriormente. As crianças têm sido tratadas com reposição enzimática e evoluem bem. No 23으 mês de vida, foi demonstrado que o gene é expresso em cerca de $1 \%$ das células da medula óssea das crianças (proporção insuficiente para abandonar a reposição enzimática), e que a expressão aumenta com a idade, o que sugere que as células transfectadas possam ter alguma vantagem seletiva sobre as demais ${ }^{19}$.

Nasagawa et al. ${ }^{37}$ utilizaram CTH que foram transfectadas com um gene modificado de receptor de um fator de crescimento de tal forma que somente substâncias mitogênicas indutoras de dimerização pudessem servir como ativadores desses receptores, estimulando a proliferação controlada das CTH. Akimov et al. ${ }^{2}$, por sua vez, estudaram os mecanismos replicativos das CTH utilizando células transfectadas com oncogenes, os quais alteram a regulação do ciclo celular. Serrano et al. ${ }^{48}$ modificaram CTH de cordão umbilical in vitro de modo que passassem a expressar um receptor que reconhecia células B. Assim, as células T derivadas dessas $\mathrm{CTH}$ poderiam combater células B malignas em leucemias linfoblásticas agudas ${ }^{48}$.

Recentemente, Asheuer et al..$^{5}$ levantaram a possibilidade de se utilizar CTH como veículos carreadores de genes cuja expressão possa ser útil no tratamento de certas doenças do SNC. Neste estudo, ficou demonstrado que células CD34+ humanas de cordão umbilical ou sangue periférico sofrem diferenciação em micróglia de ratos sem que tal processo seja influenciado pela expressão de um gene artificialmente inserido nas $\mathrm{CTH}^{5}$.

A utilização da terapia celular utilizando $\mathrm{CTH}$ de cordão umbilical no tratamento de doenças que requeiram a prévia destruição total ou parcial do sistema hematopoético dos indivíduos impele as pesquisas no sentido de desenvolver melhores regimes mieloablativos, menos tóxicos e mais eficientes. Outro campo de pesquisa em desenvolvimento relaciona-se à melhoria da prevenção da doença enxerto versus hospedeiro através do uso de citocinas imunomodulatórias, infusão de células T regulatórias ou mesmo terapia gênica.

Some-se às perspectivas de futuros avanços científicos nessa área a utilização de células-tronco embrionárias como uma nova fonte de $\mathrm{CTH}$ e o desenvolvimento em larga-escala dos bancos de cordão umbilical.

Somente através da compreensão dos mecanismos moleculares que governam o equilíbrio da divisão celular os pesquisadores poderão interferir de uma forma mais ordenada no estímulo à regeneração tecidual, no equilíbrio entre autorrenovação e diferenciação celular ${ }^{19}$ e na definição de diretrizes mais claras acerca da melhor maneira de utilizar a terapia celular e gênica para a melhoria da qualidade de vida das pessoas.

Em conclusão, a utilização de CTH de cordão umbilical constitui uma alternativa terapêutica viável e em expansão no Brasil e no restante do mundo, apesar de suas limitações e da necessidade de ampliação das pesquisas nesta área.

Silva Jr. FC da, Odongo FCA, Dulley FL. Umbilical cord blood hematopoietic stem cells: a new therapeutic alternative? Rev Med (São Paulo). 2009 jan.-mar.;88(1):45-57.

\begin{abstract}
S: In medicine, the importance of hematopoietic stem cells (HSC) is evident from their routine use in the treatment of oncohematologic and immunologic disorders achieved through bone marrow transplantation. Nevertheless, due to the difficulties encountered in finding compatible bone marrow donors, other options have been sought, for example, the use of umbilical cord blood (UCB) as a cell source. This work presents a review of pertinent medical literature and it analyzes the pros and cons of this therapeutic alternative. Despite the small volume obtained and greater time necessary for regeneration of the hematopoietic tissue, UCB presents a high concentration of HSC, lower risk of causing graft versus host disease and is easier to obtain, what contributes to its increasing use in the world. New studies on the utlization of UCB in different types of cell and gene therapies will tend to add knowledge to this field of research.
\end{abstract}

KEY WORDS: Hematopoietic stem cells. Cord blood stem cell transplantation. Gene therapy. Cell transplantation. 


\section{REFERÊNCIAS}

1. Akala OO, Clarke MF. Hematopoietic stem cell selfrenewal. Curr Opin Genet Dev. 2006;16:496-501.

2. Akimov SS, Ramezani A, Hawley TS, Hawley RG. Bypass of senescence, immortalization, and transformation of human hematopoietic progenitor cells. Stem Cells. 2005;23:1423-33.

3. Alison MR, Poulsom R, Jeffery R, Dhillon AP, Quaglia $A$, Jacob J, et al. Hepatocytes from non-hepatic adult stem cells. Nature. 2000;406(6793):257.

4. Almeida-Porada GD, Hoffman R, Manalo P, Gianni AM, Zanjani ED. Detection of human cells in human/sheep chimeric lambs with in vitro human stroma-forming potential. Exp Hematol. 1996;24:482-7.

5. Asheuer M, Pflumio F, Benhamida S, DubartKupperschmitt A, Fouquet F, Imai Y, et al. Human CD34+ cells differentiate into microglia and express recombinant therapeutic protein. PNAS. 2004;101:3557-62.

6. Bianco P, Robey PG. Marrow stromal cells. J Clin Invest. 2000;105:1663-8.

7. Bittner RE, Popoff I, Shorny S, Höger H, Wachtler F. Dystrophin expression in heterozygous $\mathrm{mdx} /+$ mice indicates imprinting of $X$ chromosome inactivation by parent-of-origin-, tissue-, strain and position-dependent factors. Anat Embryol. 1997;195:175-82.

8. Bittner RE, Schöfer C, Weipoltshammer K, Ivanova $S$, Streubel B, Hauser E, et al. Recruitment of bone-marrow-derived cells by skeletal and cardiac muscle in adult dystrophic mdx mice. Anat Embryol. 1999;199:391-6.

9. Brazelton TR, Rossi FM, Keshet GI, Blau HM. From marrow to brain: expression of neuronal phenotypes in adult mice. Science. 2000;290:1775-8.

10. Broxmeyer HE, Srour EF, Hangoc G, Cooper S, Anderson SA, Bodine DM. High-efficiency recovery of functional hematopoietic progenitor and stem cells from human cord blood cryopreserved for 15 years. PNAS. 2003;100:645-50.

11. Can A. Haematopoietic stem cells niches: Interrelations between structure and function. Transfus Apher Sci. 2008;38(3):261-8.

12. Chao NJ, Emerson SG, Weinberg KI. Stem cell transplantation (cord blood transplants). Hematology (Am Soc Hematol Educ Program). 2004:354-71.

13. Copelan EA. Hematopoietic stem-cell transplantation. N Engl J Med. 2006;354:1813-26.

14. Bone Marrow Donors Worldwide (BMDW) Statistics: Cord blood registries [cited 2008 june 02]. Available from: http://www.bmdw.org/index.php?id=statistics_ cordblood.
15. Eglitis MA, Mezey E. Hematopoietic cells differentiate into both microglia and macroglia in the brains of adult mice. PNAS. 1997;94:4080-5.

16. Ferrari G, Cusella-De Angelis G, Coletta M, Paolucci E, Stornaiuolo A, Cossu G, et al. Muscle regeneration by bone marrow-derived myogenic progenitors. Science. 1998;279:1528-30.

17. Fraser CJ, Hirsch BA, Dayton V, Creer MH, Neglia JP, Wagner JE, et al. First report of donor cell-derived acute leukemia as a complication of umbilical cord blood transplantation. Blood. 2005;106:4377-80.

18. Gluckman E, Broxmeyer HA, Auerbach AD, Friedman HS, Douglas GW, Devergie A, et al. Hematopoietic reconstitution in a patient with Fanconi's anemia by means of umbilical-cord blood from an HLA-identical sibling. N Engl J Med. 1989;321:1174-8.

19. Gluckman E. Umbilical cord blood transplant in human. Hematol Cell Ther. 1996;38:393-7.

20. Gupta P, Oegema Jr TR, Brazil JJ, Dudek AZ, Slungaard A, Verfaillie CM. Human LTC-IC can be maintained for at least 5 weeks in vitro when interleukin-3 and a single chemokine are combined with O-sulfated heparan sulfates: requirement for optimal binding interactions of heparan sulfate with early-acting cytokines and matrix proteins. Blood. 2000;95:147-55.

21. Ho AD, Punzel M. Hematopoietic stem cells: can old cells learn new tricks? J Leukoc Biol. 2003;73:547-55.

22. Humpherys D, Eggan K, Akutsu H, Hochedlinger K, Rideout III WM, Biniszkiewicz D, et al. Epigenetic instability in ES-cells and cloned mice. Science. 2001;293:95-7.

23. Ishikawa F, Yasukawa M, Yoshida S, Nakamura $\mathrm{K}$, Nagatoshi $\mathrm{Y}$, Kanemaru T, et al. Human cord blood- and bone marrow-derived CD34+ cells regenerate gastrointestinal epithelial cells. FASEB J. 2004;18:1958-60.

24. Jackson KA, Majka SM, Wang H, Pocius J, Hartley CJ, Majesky MW, et al. Regeneration of ischemic cardiac muscle and vascular endothelium by adult stem cells. J Clin Invest. 2001;107:1395-401.

25. Kiger AA, White-Cooper H, Fuller MT. Somatic support cells restrict germline stem cell self-renewal and promote differentiation. Nature. 2000;407:750-4.

26. Kocher AA, Schuster MD, Szabolcs MJ, Takuma S, Burkhoff D, Wang J, et al. Neovascularization of ischemic myocardium by human bone-marrow-derived angioblasts prevents cardiomyocyte apoptosis, reduces remodeling and improves cardiac function. Nat Med. 2001;7:430-6.

27. Kohn DB, Weisinger KI, Nolta JA, Heiss LN, Lenarsky 
Silva Jr. FC da et al. Células-tronco hematopoéticas de cordão umbilical: uma nova alternativa terapêutica?

C, Crooks GM, et al. Engraftment of gene modified umbilical cord blood cells in neonates with adenosine deaminase deficiency. Nat Med. 1995;1(10):1017-23.

28. Kolar GR, Yokota T, Rossi MID, Nath SK, Capra DJ. Human fetal, cord blood, and adult lymphocyte progenitors have similar potential for generating $B$ cells with a diverse immunoglobulin repertoire. Blood. 2003;104:2961-7.

29. Körbling M, Katz RL, Khanna AMA, Ruifrok AC, Rondon G, Albitar M, et al. Hepatocytes and epithelial cells of donor origin in recipients of peripheral-blood stem cells. N Engl J Med. 2002;346:738-43.

30. Lagasse E, Connors H, Al-Dhalimy M, Reitsma M, Dohse M, Osborne L, et al. Purified hematopoietic stem cells can differentiate into hepatocytes in vivo. Nat Med. 2000;6:1229-34.

31. Larsson J, Karlsson S. The role of smad signaling in hematopoiesis. Oncogene. 2005;24:5676-92.

32. Lee YH, Lee YA, Noh KT, Kim KH, Han JY, Seo SY, et al. Homing-associated cell adhesion molecules and cell cycle status on the nucleated cells in the bone marrow, mobilized peripheral blood, and cord blood. J Korean Med Sci. 2004;19:523-8.

33. Li L, Xie T. Stem cell niche: structure and function. Annu Rev Cell Dev Biol. 2005, 21:605-31.

34. Locateli F, Giorgiani G, Bergami E. Cord blood: a new source of hematopoietic stem cells. Hematologica Rep. 2006;2:122-5

35. Majhail NS, Weisdorf DJ, Wagner JE, Defor TE, Brunstein CG, Burns LJ. Comparable results of umbilical cord blood and HLA-matched sibling donor hematopoietic stem cell transplantation after reducedintensity preparative regimen for advanced Hodgkin lymphoma. Blood. 2006;107:3804-7.

36. Mezey E, Chandross KJ, Harta G, Maki RA, McKercher SR. Turning blood into brain: cells bearing neuronal antigens generated in vivo from bone marrow. Science. 2000;290:1779-82.

37. Nasagawa Y, Wood BL, Wang L, Litmaer I, Guo W, Papayannopoulou T, et al. Anatomical compartments modify the response of human hematopoietic cells to a mitogenic signal. Stem Cells. 2006;24:908-17.

38. National Institutes of Health. Stem Cell Information [cited 2008 june 02]. Available from: http://stemcells.nih.gov.

39. National Institutes of Health. Stem Cells: Scientific Progress and Future Research Directions, Terese Winslow, 2001.

40. Ng YY, van Kessel B, Lokhorst HM, Baert MRM, Van de burg CMM, Bloem AC, et al. Gene-expression profiling of CD34+ cells from various hematopoietic stem-cell sources reveals functional differences in stem-cell activity. J LeuKoc Biol. 2004;75:314-23.

41. Nierhoff D, Horvath HC, Mytilineos J, Goling M, Bud O, Klar E, et al. Microchimerism in bone marrow-derived CD34+ cells of patients after liver transplantation. Blood. 2000;96:763-7.

42. O'Brien TA, Tiedemann K, Vowels MR. No longer a biological waste product: umbilical cord blood. Med $\mathrm{J}$ Aust. 2006;184:407-10.

43. Orlic D, Kajstura J, Chimenti S, Jakoniuk I, Anderson $\mathrm{SM}, \mathrm{Li} \mathrm{B}$, et al. Bone marrow cells regenerate infarcted myocardium. Nature. 2001;410:701-5.

44. Orlic D, Kajstura J, Chimenti S, Limana F, Jakoniuk I, Quaini $F$, et al. Mobilized bone marrow cells repair the infarcted heart, improving function and survival. PNAS. 2001;98:10344-9.

45. Petersen BE, Bowen WC, Patrene KD, Mars WM, Sullivan AK, Murase N, et al. Bone marrow as a potential source of hepatic oval cells. Science. 1999;284:1168-70.

46. Reed W, Smith R, Dekovic R, Lee JY, Saba JD, Trachtenberg $E$, et al. Comprehensive banking of sibling donor cord blood for children with malignant and nonmalignant disease. Blood. 2003;101:351-7.

47. Sanz MA. Cord-blood transplantation in patients with leukemia - a real alternative for adults. $\mathrm{N}$ Engl J Med. 2004;351:2328-30.

48. Serrano LM, Pfeiffer T, Olivares S, Numbenjapon T, Bennitt J, Kim D, et al. Differentiation of naïve cordblood T cells into CD19-specific cytolytic effectors for posttransplantation adoptive immunotherapy. Blood. 2006;107:2643-52.

49. Siegert W, Nitsche A, Junghahn I, Thulke S, Aumann $\mathrm{J}$, Radoni A, et al. Interleukin-3 promotes proliferation and differentiation of human hematopoietic stem cells but reduces their repopulation potential in NOD/SCID mice. Stem Cells. 2003;21:236-44.

50. Theise ND, Badve S, Saxena R, Henegariu O, Sell $S$, Crawford JM, et al. Derivation of hepatocytes from bone marrow cells of mice after radiation-induced myeloablation. Hepatology. 2000;31:235-40.

51. Traycoff CM, Abboud MR, Laver J, Clapp DW, Srour EF. Rapid exit from G0/G1 phases of cell cycle in response to stem cell factor confers on umbilical cord blood CD34+ cells an enhanced ex vivo expansion potential. Exp Hematol. 1994;22:1264-72.

52. Trigg ME. Hematopoietic stem cells. Pediatrics. 2004;113:1051-7.

53. National Marrow Donor Program (NMDP). Umbilical cord blood donation, advanced [cited 2008 June 02]. Available from: http://www.marrow.org/DONOR/ Donation_Transplant_Process/The_Donation_ 
Procedure/CB_Donation/Advanced/index.html.

54. Vormoor J, Lapidot T, Pflumio F, Ridson B, Patterson $\mathrm{G}$, Broxmeyer HE, et al. Immature human cord blood progenitors engraft and proliferate to high levels in severe combined immunodeficient mice. Blood. 1994;83:2489-97.

55. Wang X, Al-Dhalimy M, Lagasse E, Finegold M, Grompe M. Liver repopulation and correction of metabolic liver disease by transplanted adult mouse pancreatic cells. Am J Physiol. 2001;158:571-9.

56. Weissman IL. Stem cells: units of development, units of regeneration, and units in evolution. Cell. 2000;100:157-68.

Recebido em: 03/06/2008

Aceito em: 14/10/2008
57. Yang L, Dybedal I, Bryder D, Nilsson L, Sitnicka E, Sasaki $Y$, et al. IFN- $\gamma$ negatively modulates selfrenewal of repopulating human stem cells. J Immunol. 2005;174:752-7.

58. Zanjani ED, Porada P, Crapnell KB, Theise ND, Krause DS, MacKintosh FT, et al. Production of human hepatocytes by human CD34+/- cells in vivo. Blood. 2001;96:494

59. Zhou SZ, Cooper S, Kang LY, Ruggieri L, Heimfeld S, Srivastava A, et al. Adenoassociated virus 2-mediated high efficiency gene transfer into immature and mature subsets of hematopoietic progenitor cells in human cord blood. J Exp Med. 1994;179:1867-75. 